\title{
Creatividad Mindfulness: transformadora metodología de estimulación conceptual del proceso de ideación publicitaria del siglo XXI.
}

\author{
José Jesús VARgas Delgado \\ Universidad Europea de Canarias \\ jjesus.vargas@uem.es
}

\begin{abstract}
Resumen:
Nuestra investigación se encuentra focalizada en los efectos de un estudio experimental que examina en profundidad el descubrimiento de un nuevo paradigma metodológico de estimulación conceptual del siglo XXI: Mindfulness. Los procesos analíticos convencionales de los estadios secuenciales para alcanzar los objetivos de creatividad primarios en un individuo siempre han sido tangencialmente materializados a través de un enfoque racional; creatividad racional. Una perspectiva focalizada por variables de estudios absolutamente racionales permitió, como era previsible detectar, que existieran evidentes carencias en el proceso de producción, y surgiera la innovadora visualización del proceso creativo desde una perspectiva emocional; creatividad emocional. El nuevo paradigma de desarrollo del individuo y proyección en su irrepetible entorno del siglo XXI, estimula una inspiradora reformulación de una consciente y transformadora etapa en el proceso de creación. Creatividad Mindfulness. Se configura como una nueva metodología de estimulación de crecimiento personal que transforma los axiomas básicos de producción creativa. Atención plena (mindfulness) se posiciona como un sofisticado método que permitirá encontrar la forma de serenar y rescatar el potencial y valor de las creaciones publicitarias. Una vez superadas las vitales y secuenciales etapas de creatividad racional y emocional, nos encontramos con una renovadora etapa de conciencia de creación orientada plenamente sobre el presente. Eliminar los automatismos creativos de las conductas aumentando la conciencia de estimulación creativa. Vaciar los prejuicios y juicios de valor, evitando que se interpongan en la capacidad productiva y potencial de eficacia creativa. Abrir y estar disponibles en las nuevas perspectivas creativas. Resiliencia creativa como elemento potencial de estimular la capacidad que posee el individuo para afrontar las adversidades de entornos de creación publicitaria. El objetivo de la ponencia está posicionado en el desarrollo de las principales inferencias y conclusiones cualitativas y cuantitativas en un transformador método de creatividad consciente vinculada sobre la atención plena, que pasa por la búsqueda de un silencio en la mente del creativo, que le permita poder alcanzar una potencial capacidad para escuchar con nitidez la intuición publicitaria necesaria en el nuevo paradigma educativo del siglo XXI.
\end{abstract}

Palabras clave: mindfulness; atención plena; creatividad racional; creatividad emocional; creatividad midfulness y conciencia creativa.

\section{Mindfulness Creativity: Transforming stimulation methodology concept advertising process conception of the XXI Century}

\begin{abstract}
:
Our research is focused on the effects of an experimental study that examines in depth the discovery of a new stimulation paradigm conceptual methodological XXI Century: Mindfulness. The conventional analytical processes sequential stages to achieve the objectives of an individual primary creativity has always been tangentially materialized through a rational, rational creativity. A perspective study focused by perfectly rational variables allowed, predictably detect obvious deficiencies existed in the produc-
\end{abstract}


tion process, and display the innovative emergence of the creative process from an emotional perspective, emotional creativity. The new paradigm of human development and its unique projection century environment, stimulates a conscious reformulation inspiring and transformative stage in the process of creation. Mindfulness Creativity. It is configured as a new methodology of personal growth stimulation transforms the basic axioms of creative production. Mindfulness is positioned as a sophisticated method that will find a way to calm and rescue the potential and value of advertising creations. Having overcome the sequential stages of life and creativity and empathy, we find a renewal stage fully oriented awareness creation on the present. Remove the automatic creative behaviors by increasing awareness of creative stimulation. Empty prejudices and value judgments, avoiding that stand in the productive capacity and potential for creative effectiveness. Open and available in new creative perspectives. Resilience creative and stimulating potential element that has the individual capacity to face adversity advertising creation environments. The aim of the paper is positioned to develop inferences and conclusions major qualitative and quantitative method in a transformer linked to conscious creativity mindfulness, which passes through the pursuit of a silence in the mind of creative, enabling it to reach a potential ability to hear clearly advertising intuition needed in the new educational paradigm century.

Key Words: Mindfulness; rational creativity; emotional creativity; midfulness creativity and creative mind.

\section{Referencia normalizada:}

Vargas Delgado, J.J. (2014): Creatividad Mindfulness: transformadora metodología de estimulación conceptual del proceso de ideación publicitaria del siglo XXI. Historia y Comunicación Social. Vol. 19. Núm. Especial Enero. Págs. 695-709.

Sumario: 1. Introducción, 2. Proceso de ideación de creatividad publicitaria racional, 3. Proceso de ideación de creatividad publicitaria emocional, 4. Metodología de creatividad publicitaria Mindfulness, 5. Creatividad Mindfulness. Metodología de aplicación en la esfera de la estimulación conceptual, 6. Resultados de la aplicación de la técnica de estimulación Creatividad Mindfulness (CMF) y 7. Bibliografía.

\section{Introducción}

Nuestra investigación se encuentra focalizada en los efectos y aplicación de un innovador estudio experimental que examina en profundidad el descubrimiento de un nuevo paradigma metodológico de estimulación conceptual del Siglo XXI: Creatividad Mindfulness (CMF). Los procesos analíticos convencionales de los estadios secuenciales, para alcanzar los objetivos de creatividad primarios en un individuo, siempre han sido tangencialmente materializados a través de un enfoque racional; creatividad publicitaria racional. Una perspectiva focalizada por variables de estudios absolutamente racionales permitió, como era previsible detectar, que existieran evidentes carencias en el proceso de producción, y surgiera la innovadora visualización del proceso creativo desde una perspectiva emocional; creatividad publicitaria emocional. El nuevo paradigma de desarrollo del individuo y proyección en su irrepetible entorno del Siglo XXI, estimula una inspiradora reformulación de una consciente y transformadora etapa en el proceso de creación. Creatividad Mindfulness. Se configura como una nueva metodología de estimulación de crecimiento personal, que aplicada innovadoramente, a entornos y esferas de ideación publicitaria, transforma 
inexorablemente los axiomas básicos de producción y eficiencia creativa. Atención plena (Mindfulness) se posiciona como un sofisticado procedimiento que permitirá encontrar la forma de serenar y rescatar el potencial y valor de las obras publicitarias. Una vez superadas las vitales y secuenciales etapas de creatividad racional, y emocional, nos encontramos con una renovadora etapa de exaltación de la conciencia de creación, orientada plenamente sobre el presente, sobre el microinstante. Eliminar los automatismos compositivos de las conductas, aumentando la conciencia de provocación creativa. Vaciar los prejuicios y juicios de valor, evitando que se interpongan en la capacidad productiva y potencial de eficacia compositiva. Abrir nuestra mente, y estar disponibles a las nuevas perspectivas inventivas, utilizando la herramienta de la respiración como centro neurálgico. Resiliencia productiva como elemento potencial de incitar la capacidad que posee el individuo para afrontar las adversidades de entornos de integración publicitaria. El objetivo de la ponencia está posicionado en el desarrollo de las principales inferencias y conclusiones cualitativas y cuantitativas de un transformador y renovador método de creatividad consciente, vinculado sobre la atención plena, que pasa por la búsqueda de un silencio en la mente del creativo, que le permita poder alcanzar una potencial capacidad para escuchar con nitidez la intuición publicitaria necesaria en el nuevo paradigma educativo del siglo XXI.

\section{Proceso de ideación de creatividad publicitria racional}

El proceso de ideación de la creatividad publicitaria ha pasado por multitud de fases/secuencias que permiten incluir las características alcanzadas de cada fase en los estadios posteriores. El proceso de creación de ideas racionales, contiene un sumario lógico, apoyado en parámetros coherentes y convencionales para posteriormente llegar a la configuración de conceptos originales. Se trata, por lo tanto, de llegar a sugestionar al receptor por medio de beneficios racionales y tangibles. Las variables de reacción que se engendran en el receptor se basan en la inducción de impulsos racionales, y no emocionales. Uno de los grandes investigadores de proceso de concepción de ideas publicitarias desde diferentes itinerarios es Luis Bassat. En su libro "El libro rojo de la Publicidad" instala un catálogo de los caminos creativos racionales. Dentro de esa clasificación, para aprehender procesos racionales de creatividad exitosa, podemos encontrar, entre otros, la búsqueda del origen, a través de demostraciones, comparación, presentador de televisión, testimoniales, ... Todos los senderos racionales se basan en trazos de ventajas competitivas tangibles sobre tu competencia. En un proceso racional de creación publicitaria, el creador de ideas focaliza su esfuerzo sobre aspectos palpables donde los dividendos son mensurables y objetivamente demostrables a corto plazo. Ante un problema de comunicación, el creativo promete soluciones directas. A pesar de la base racional de este proceso para la creación de ideas basadas en la lógica, es necesario reconocer que muchos de estos itinerarios tienen una pequeña base emocional. Cuando los productos son muy similares, los argumentos racionales de creación y diferenciación semántica quedan 
marchitos. Para los creativos publicitarios, en la actualidad, utilizar el proceso de ideación racional está absolutamente limitado. En las situaciones de recesión económica, los anunciantes, frecuentemente, animan al empleo de la construcción de mensajes con tintes racionales, debido a la urgencia por fundamentar el proceso de compra final en la rentabilidad y optimización. Pero la objetividad publicitaria nos demuestra que es un proceso que tiene todas las ramificaciones y salidas absolutamente extenuadas.

\section{Proceso de ideación de creatividad publicitaria emocional}

La vía de la creatividad a través de una metodología racional gozó de grandes éxitos, y cubrió las exigencias del receptor, y a su vez del emisor, durante un periodo pasado. El desarrollo natural de las similitudes de los artículos y servicios, invita y obliga, irremisiblemente, a la creación de flamantes postulados a la hora de encontrar la idea publicitaria o el concepto paradigmático para nuestra campaña. La emoción como inconstante en la creación de los mensajes se configura como el nuevo coeficiente clave para poder conectar con el receptor. Se trata de provocar en el espectador, a través de los sentimientos y emociones, una serie de reacciones persuasivas deliberadamente orientadas sobre la eficiencia comunicativa. Los efectos persuasivos de nuestros mensajes, tienden a una elaboración más fluida a medio y largo plazo. Luis Bassat identifica una serie de caminos que nos transportan a través de este prisma. Emoción pura que nos hace llorar, perspectiva sexual, violencia, humor, la música como factor de atajo para alcanzar la emoción, ... Actualmente, tanto en la metodología del creativo que tiene el objetivo de la creación de un concepto renovador para estimular la atención y el deseo del receptor, como en la exquisita y delicada estética final del mensaje publicitario, podemos localizar un destacable predominio de factores emocionales esenciales en la disposición de los mensajes. La grandísima mayoría de los productos son análogos y la emoción es, hasta ahora, una fórmula recurrente y responsablemente imperiosa que, además de superar con estilo los postulados constructivos y creativos de la razón, permite conquistar el hemisferio derecho de nuestro cerebro de una forma eficiente.

\section{Metodología de creatividad publicitaria mindfulness}

Mindfulness es una cualidad de la mente, o más bien la capacidad intrínseca de la mente de estar presente y consciente en un momento determinado, en un instante en el que cuerpo y mente se sintonizan totalmente en un único relámpago de la realidad presente. Presencia plena y consciencia abierta se conjugan en un momento en nuestra mente/cuerpo/espíritu. Es esa cualidad propia de cualquier ser humano pero que ha sido motivo de estudio principalmente en el paradigma oriental. Experiencia focalizada 
plenamente sobre el instante. Mindfulness se centra en la formalización de encauzar nuestra atención en el proceso, llevar a cabo una técnica de consciencia enérgica. El sagrado proceso consciente entre los estímulos, ya sean de carácter interno o externo, y las respuestas, de naturaleza interna o externa. Creando un sugerente tiempo para responder más apropiadamente. Mucho más habilidosamente, mucho más virtuosamente y de forma mucho más justa. Conseguir el enfoque de nuestra mente en este espacio consciente y pleno entre el estímulo del briefing y la contestación en forma de concepto creativo. La estimulación de este espacio engendra una mayor capacidad para establecer la respuesta más virtuosa. Es la creación intencionada de una venerable fragmentación que nos aleja de respuestas automáticas basadas en la reacción y la racionalidad experiencial. Despertar un firmamento infinito y consciente entre el estímulo y la respuesta, nos permite evocar nuestra capacidad de resolver de una manera mucho más despierta, evitando contestaciones automatizadas. Automotriz cognitiva que está basada, fundamentalmente, en un movimiento dicotómico, cuya base es puramente hedonista. "A través de la práctica de Mindfulness se desarrolla la habilidad de permanecer presentes con una ecuanimidad inalterable ante toda experiencia o estimulación (tanto agradable como desagradable, de origen interno como externo), por lo que deja de responder con avidez y aversión (aproximándose y alejándose), permaneciendo inmóvil, atenta, calma y serena (Mañas, Gómez, Sánchez, Fernández y Franco, 2008). Es, por lo tanto, un estadio de superación consciente donde no nos dejamos arrastrar por nuestros pensamientos y emociones, simplemente nos permite estar presente y atentos en ese espacio de calma, para poder emitir la respuesta de una forma mucho más lúcida y virtuosa. En este espacio se posiciona el innovador método de Creatividad Mindfulness (CMF) que presentamos. Los creativos publicitarios han pasado por un proceso de automatización en la creación de sus campañas y conceptos creativos. Esta mecanización se ha visto condicionada por varios factores. Por un lado, el vertiginoso ritmo que requiere la puesta en marcha de los procesos publicitarios. Por otro lado, la recurrente racionalización experiencial, que lejos de ser una fortaleza y herramienta útil en la creación de los conceptos publicitarios, se conforma como un recurso fácil, involuntario e irreflexivo de creación. Del mismo modo, la explotación de la emoción experimental, una vez superado el tramo atractivo de la virginidad en el enfoque, se constituye como un procedimiento instintivo que mecaniza las respuestas originales. Atmósfera que viciosamente se retroalimenta, disminuyendo exponencialmente el talento de las ideas que surgen. El modelo de nuestra Creatividad Mindfulness (CMF) es una interminable, reveladora e innovadora herramienta virtuosa que permite, desde una vertiente puramente productiva alcanzar ideas sobresalientes, y, además, experimenta en un espacio consciente de infinitas posibilidades sobre el destinatario. Creatividad Mindfulness (CMF): nueva metodología de estimulación conceptual. Reformulización del proceso de ideación publicitaria del siglo XXI. 


\section{Creatividad mindfulness. Metodología de aplicación en la esfera de la estimu- lación conceptual}

Partimos de dos variantes posibles para la aplicación de nuestro método de Creatividad Mindfulness (CMF). Escenario I.: El creativo publicitario se autoaplica nuestro método (CMF) para la estimulación de ideas creativas. Escenario II.: Un consultor de Creatividad Mindfulness (CMF) aplica terapéuticamente el método al posible creador de ideas conceptuales publicitarias. En ambos supuestos, la práctica de la Creatividad Mindfulness (CMF) comienza con la práctica de meditación en la concentración. A continuación, exponemos las cinco fases de las que se compone el método CMF:

Fase 1. Identificación preconceptual. Reconocimiento de cinco variables preconceptuales. Antes de la activación de la metodología Creatividad Mindfulness (CMF) existe una fase primaria muy sencilla que consiste en la identificación de cinco valores conceptuales antes de la creación de un concepto creativo publicitario. Aplicación práctica: Año 2004. Campaña de la conserjería de Turismo y Deporte, a través de su entidad de promoción Turismo Andaluz. El objetivo conceptual es convertir Andalucía en destino turístico líder. Se parte de un concepto creativo que ha tenido grandes resultados durante dos años. Posicionamiento estratégico turístico: "Andalucía sólo hay una, la tuya" donde Andalucía se funde a una persona hasta el punto de hacerla suya, de personalizarla, a través del lugar que más se identificara con ella. Ahora la idea es buscar un concepto nuevo. Empleamos el método CMF para la estimulación y creación de ideas. Para lo cual identificamos cinco valores conceptuales de descripción atmosférica, para la posible creación de la campaña. En esta fase lo ideal es trabajar e identificar, previamente, los posibles conceptos con el departamento de planificación estratégica, directores de marketing y/o anunciante. Las cinco palabras claves que surgen como resultado son las siguientes: "Amor absoluto por Andalucía", "Andalucía persona", trato plenamente "cercano", "vital" y "vinculación perpetúa". Reducimos a la mínima expresión conceptual las cinco variables, a cinco conceptos: "Andalucía Amor", "Andalucía persona", "Andalucía cercano", "Andalucía vital” y "Andalucía siempre".

Fase II. Conexión consciente. A partir de este proceso comienza la aplicación pragmática de la técnica. Una fase de conexión necesaria, e indispensable, para que el creativo pueda disociar los procesos automáticos, abandonando el diálogo interno de pensamientos, y la corriente perpetúa de pensamientos, emociones. Esta segunda fase de conexión tiene el objetivo de aquietar la mente, calmarla, serenarla y tranquilizarla. Con esa intención se entrenará disciplinada y conscientemente la mente a permanecer centrada en un solo estímulo de manera ininterrumpida. En esta fase de conexión, lo excelente es que focalicemos nuestra atención en la respiración. Adoptamos una postura de conexión y nos sentamos con la espalda muy recta sobre una silla cómoda, que permita mantener nuestra columna muy recta y dejamos caer nuestros hombros. Cerramos los ojos. Focalizamos toda la atención sobre nuestro estómago. Nos observamos y visualizamos dentro de una grandiosa esfera, brillante y resplandeciente de luz. Un océano de luz blanca y serena. Sentimos de forma consciente como 
"inhalamos" esa luz brillante, que al ser "exhalada" se expande por nuestras fosas nasales. El creativo debe mantener toda su atención de forma disciplinada en este estado de inhalación y exhalación consciente. Cada vez que seamos conscientes de que nuestra mente se dispersa de la focalización de nuestra respiración, devolvemos con rigor nuestra concentración al estómago y al proceso de inhalación. Intenta ser consciente de cada uno de los pensamientos y sentimientos, obsérvalos sin enjuiciar, de una forma ecuánime y serena. En esta fase de conexión, antes del proceso creativo conceptual, se deberá invertir, al menos, unos 12 minutos. Es muy importante invertir serena y disciplinadamente en esta fase, dado que nos va a permitir integrar de una manera mucho más fluida y consciente los siguientes procesos de visualización compositiva consciente.

Fase III. Visualización inspiradora. "Las técnicas de visualización recrean una imagen para, a través de ella, lograr un estado emocional positivo y reacondicionar el subconsciente". (Ramiro Calle. Yoga para una vida Sana, 2000. Página 205). Fase vital del proceso, que consiste en activar y recrear con vigor, y lucidez, las cinco variables que representan la esencia creativa de nuestra campaña. Una vez superada la fase de conexión, donde nuestra mente se encuentra en un estado meditativo para poder integrar las palancas secretas para la creación de la idea, el creativo, de forma individual, o sugerida a través de la sutil dirección de un terapeuta, tendrá que visualizar las cinco características del concepto que quiere trabajar. Recreación imaginaria, con la mayor realidad y consciencia posible, materializando cada concepto en diferentes zonas de la esfera brillante que le rodea, y que tiene visualizada. De una manera absolutamente sencilla, y simple, intentando no crear narraciones semánticas, y sin imágenes apegadas a tramas narrativas. El primer concepto lo ubicamos a la altura de nuestra coronilla a unos $50 \mathrm{~cm}$. de distancia frente a nuestro cuerpo (ver gráfico). El segundo concepto lo ubicamos a la altura de nuestros ojos, a unos $50 \mathrm{~cm}$. de distancia frente a nuestro cuerpo (ver gráfico). El tercer concepto lo ubicamos a la altura de nuestro pecho, a unos $50 \mathrm{~cm}$. de distancia frente a nuestro cuerpo (ver gráfico). El cuarto concepto lo ubicamos a la altura de nuestro estómago, a unos 50 $\mathrm{cm}$. de distancia frente a nuestro cuerpo (ver gráfico). El quinto concepto lo ubicamos a la altura de nuestras manos, a unos $50 \mathrm{~cm}$. de distancia frente a nuestro cuerpo (ver gráfico). Es muy importante que la materialización del concepto, delante de nosotros, se realice con la mayor nitidez, sencillez, lucidez y pureza. Intentando evitar la inclusión de concepciones que contengan variables de sofisticada elaboración. 


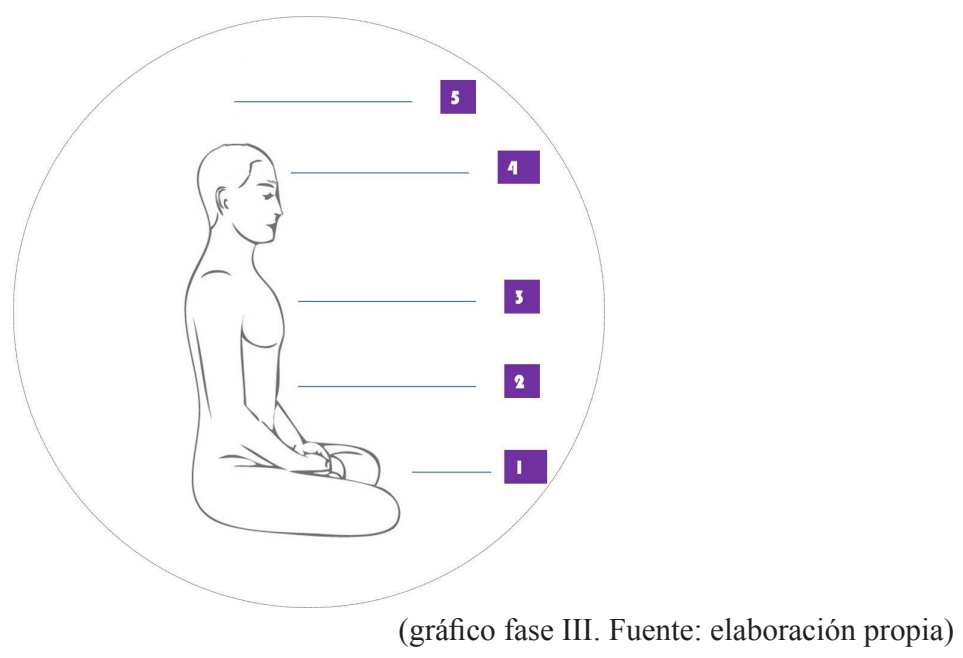

Lo aplicamos a nuestro supuesto práctico de la campaña de comunicación turística de Andalucía 2004. Los conceptos puros que debemos recrear y visualizar son los siguientes: "Andalucía amor", "Andalucía persona", "Andalucía cercano", "Andalucía vital" y "Andalucía siempre". No es tan importante la visualización de la palabra "Andalucía amor", ni la visualización de la imagen que representa el concepto "Andalucía amor", lo importante es que se sienta plenamente la fusión de la pureza sencilla de la idea "Andalucía amor". Una recreación de la idea que finalmente, en posteriores estadios del método, va a ser engullida por nuestro cuerpo, mente y espíritu como creativo publicitario.

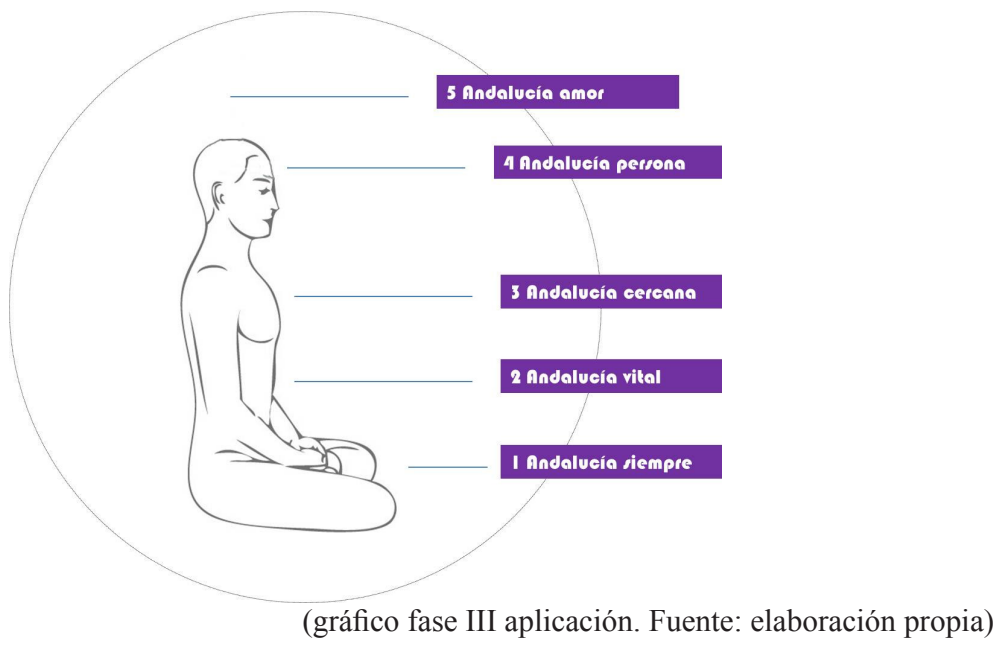

En esta fase debemos ser capaces de visualizar, y recrear, cada uno de los conceptos puros en cada uno de los entornos señalados de nuestra esfera luminosa frente a nuestro cuerpo. Es muy importante que el creativo que aplique la técnica de estimu- 
lación de Creatividad Mindfulness (CMF), sea capaz de lograr depositar el máximo de niveles de atención y concentración de cada uno de los conceptos, diferenciando, claramente, en cada una de las zonas. La ubicación de cada uno de los conceptos corresponde, en gran medida, con la identificación espacial y simbólica de los chakras (Los chakras se encuentran en los cuerpos sutiles del ser humano, llamados kamarupa). La ubicación del concepto 5 corresponde con el chakra $\mathrm{n}^{\circ} 7$. Sus significados fundamentales están relacionados con aspectos trascendentes. El color predominante es el blanco o violeta. La ubicación del concepto 4 corresponde con el chakra $\mathrm{n}^{\circ} 6$. Sus significados fundamentales están relacionados con aspectos de intuición. El color predominante es el añil. La ubicación del concepto 3 corresponde con el chakra $\mathrm{n}^{\circ} 4$. Sus significados fundamentales están relacionados con aspectos devoción y amor. El color predominante es el verde. La ubicación del concepto 2 corresponde con el chakra $\mathrm{n}^{\circ} 3$. Sus significados fundamentales están relacionados con aspectos mente, poder y control. El color predominante es el blanco o amarillo. La ubicación del concepto 1 corresponde con el chakra $\mathrm{n}^{\circ} 1$. Sus significados fundamentales están relacionados con aspectos supervivencia e intento de seguridad. El color predominante es el rojo. Sería muy recomendable tener en cuenta la ubicación de cada uno de las cinco variables en cada uno de los 5 chakras, en función de los factores semánticos señalados. Los efectos productivos conceptuales y de integración que se pueden percibir, con una combinación diferente, está directamente condicionado por la influencia de significado simbólica de cada uno de los chakras. El tiempo de creación en la órbita de nuestra esfera luminosa debe estar posicionado durante aproximadamente 5 minutos cada conceptos. De forma progresiva el creativo irá resaltando cada uno de los conceptos, dejando el resto sin apagar, con un mínimo de brillo de fondo. Finalmente invertimos 25 minutos en esta fase de visualización inspiradora. Al igual que hemos señalado en anteriores etapas, es importante que nuestra mente esté plenamente atenta a cada uno de los conceptos, sin entrar en ningún juicio de valor. Es recomendable utilizar alguna melodía suave, o algún mantra que pueda inspirar en este proceso de recreación y receptividad conceptual. El mantra es un fonema místico que se utiliza para conectar de forma cíclica con las emociones conscientes, su utilización en esta técnica de estimulación creativa permite concentrar energía y aumentar nuestra capacidad meditativa sobre los conceptos identificados. Lo realmente esencial es que la melodía que se utilice sea una fuente de inspiración y concentración para el creativo.

Fase IV. Integración subconsciente. Una vez que los conceptos son claramente recreados y visualizados, procedemos a integrarlos y activarlos a través de un potente protocolo, a través de respiraciones conscientes, que permiten la receptividad de los preconceptos para que activen nuestra creatividad. La herramienta vital para este proceso será la respiración consciente. Para la integración de cada uno de los conceptos es importante que definamos un tipo de respiración completa en 4 fases que por su potencial es importante que los que utilicen, y apliquen esta técnica de creatividad, sean capaces de manejar y ejercitar. La respiración completa que debemos realizar para la integración de cada concepto es una respiración completa consciente (RCC). Básicamente consiste en invertir: 15 segundos de inhalación consciente, 15 segundos 
de retención consciente con aire, 15 segundos de exhalación consciente, 15 segundos de retención consciente sin aire. Cuando tus pulsaciones estén suficientemente controladas, y encuentres el momento idóneo para integrar el concepto elegido puedes realizar esta respiración completa en 1 minuto. Intenta que el canal de aire que pase por tus fosas nasales sea lo pequeño posible para poder alargar durante 15 segundos las inhalaciones y exhalaciones. Al principio lo ideal es utilizar un cronómetro que te sirva de referencia. Después lo ideal es hacerlo de forma intuitiva o al ritmo de una melodía, o mantra, con el que puedas sincronizar los tiempos estipulados. Vamos a aplicarlo a nuestro supuesto práctico. Año 2004. Campaña de la conserjería de Turismo y Deporte, a través de su entidad de promoción Turismo Andaluz. Tenemos una visualización de los 5 conceptos puros. Procedemos a la integración subconsciente del primer concepto posicionado "Andalucía siempre". Una vez que tengamos completamente visualizado el concepto a la altura de nuestras piernas, que coincide con el primer chakra, procedemos a realizar la interiorización del mismo a través de la respiración profunda. Tenemos que percibir como el concepto de "Andalucía siempre" se materializa y es "inhalado" y recibido por nuestras fosas nasales. Una respiración consciente pausada que permite percibir como el aire en forma conceptual del concepto elegido es "inhalado materialmente" en forma de un aire puro de color blanco brillante. Durante esos 15 segundos la plenitud del concepto es absorbida por el creativo. Una vez que el concepto es "inhalado" ahora procedemos a "retener" el concepto en nuestro interior. Para ello lo ideal es contraer nuestro abdomen y nuestro ombligo para que el concepto pueda penetrar y grabarse en nuestro subconsciente. Como tercera fase "exhalamos" el concepto por nuestras fosas nasales de forma muy pausada. En forma de color azul. Finalmente "retenemos" después de la "exhalación" sin aire para perpetuar la idea elegida en el primer concepto.

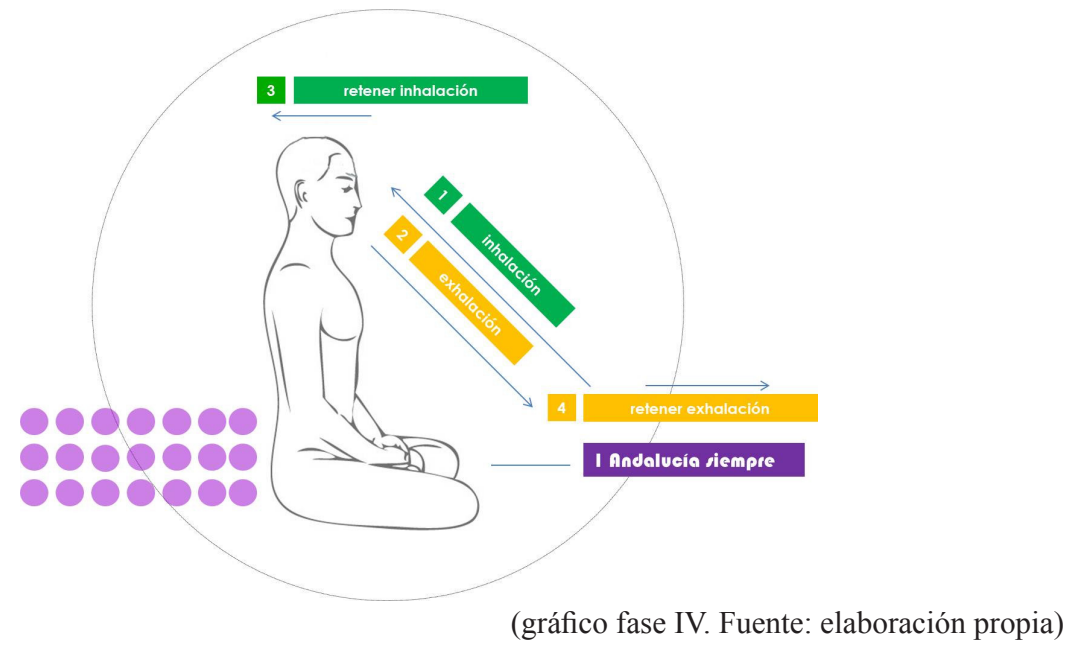

De igual manera que hemos realizado la integración subconsciente del primer concepto, procedemos paulatinamente y de forma ordenada, a la integración a través de la herramienta de la respiración completa, del resto de los conceptos. Concepto 2. 
"Andalucía vital". 15 segundos de inhalación consciente, 15 segundos de retención consciente con aire, 15 segundos de exhalación consciente, 15 segundos de retención consciente sin aire.

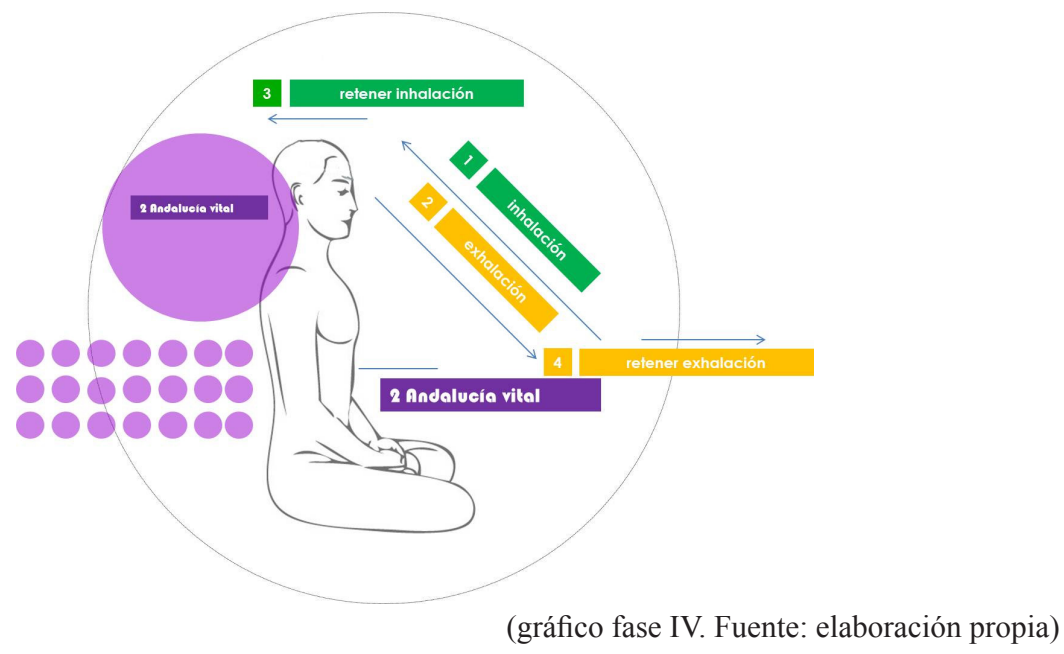

Concepto 3. "Andalucía cercana". 15 segundos de inhalación consciente, 15 segundos de retención consciente con aire, 15 segundos de exhalación consciente, 15 segundos de retención consciente sin aire.

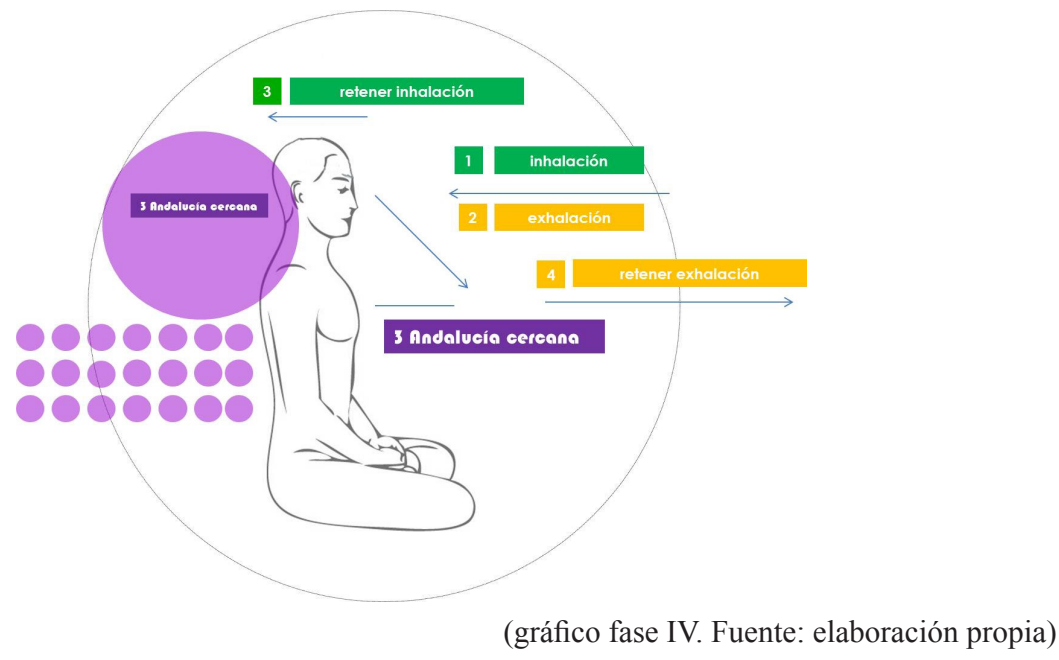

Concepto 4. "Andalucía persona". 15 segundos de inhalación consciente, 15 segundos de retención consciente con aire, 15 segundos de exhalación consciente, 15 segundos de retención consciente sin aire. 


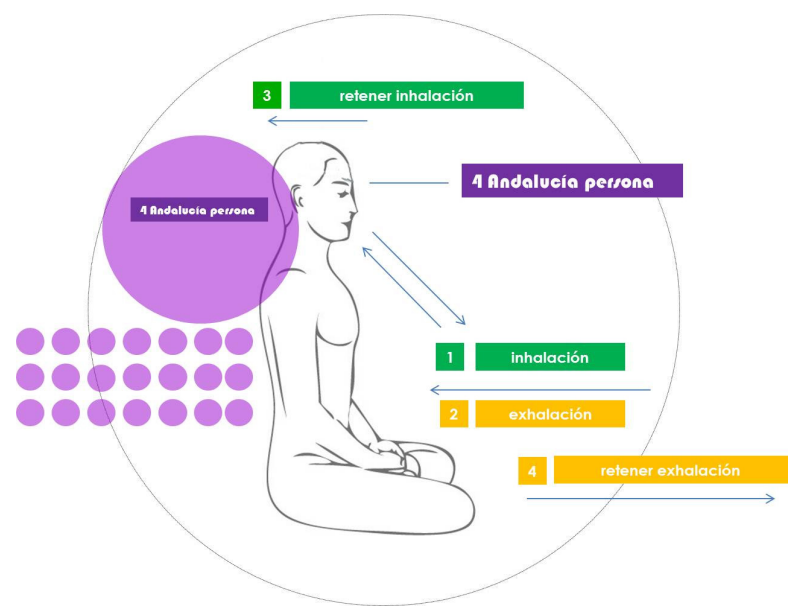

(gráfico fase IV. Fuente: elaboración propia)

Concepto 5. "Andalucía amor". 15 segundos de inhalación consciente, 15 segundos de retención consciente con aire, 15 segundos de exhalación consciente, 15 segundos de retención consciente sin aire.

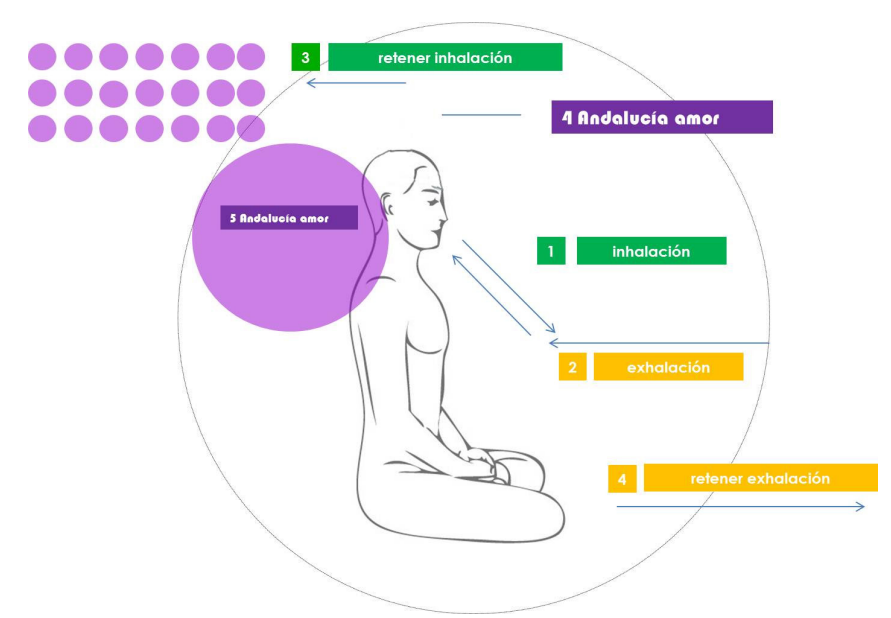

(gráfico fase IV. Fuente: elaboración propia)

Debido a la complejidad a la hora de integrar la respiración completa en 4 fases, es importante dedicar al menos 15 minutos a esta fase. Es decir 3 minutos por cada concepto. Teniendo en cuenta que uno de los minutos está dedicado, íntegramente, a la interiorización del preconcepto creativo.

Fase V. Desconexión consciente. Fase final del proceso de estimulación Creativa Mindfulness. El objetivo es no romper, de forma rígida y drástica, el estado de integración e interiorización, porque podemos romper los caminos sutiles de conexión suprema con la mente del creativo. Es un proceso paulatino de desconexión. Volvemos 
a ser consciente de la postura de conexión, con la espalda muy recta sobre una silla cómoda, que permita mantener nuestra columna muy recta, y dejamos caer nuestros hombros. Focalizamos por última vez, en este proceso, toda nuestra atención sobre nuestro estómago. Nos observamos dentro de la grandiosa esfera brillante de luz, ese océano de luz blanca y pura, que no hemos disuelto durante toda la aplicación de la técnica CMF. Sentimos de forma consciente como "inhalamos" esa luz brillante que al exhalar se expande por nuestras fosas nasales. Finalmente tomamos consciencia del lugar y de espacio, y de forma inmediata hacemos desaparecer la visualización de la esfera brillante, y gradual, y calmadamente abrimos los ojos. Esta $\mathrm{V}$ fase es un ciclo automático de procedimiento que tenemos que ir perfeccionando con la utilización disciplinada de la técnica. Invertimos en esta fase 5 minutos.

\section{Resultados de la aplicación de la técnica de estimulación creatividad mindful- ness (CMF)}

Con la estricta y disciplinada aplicación de la técnica que acabamos de presentar, el tiempo que el creativo tiene que invertir en su riguroso desarrollo es escasamente de 60 minutos. Todo ello, por supuesto, dedicando un periodo suficiente de trabajo previo en equipo con el departamento de marketing, planificación estratégica y/o el anunciante para ver las claves o palancas esenciales que vamos a elegir como preconceptos en las fases II a la V. De esta manera la distribución de los tiempos, y el proceso secuencial sería el siguiente:

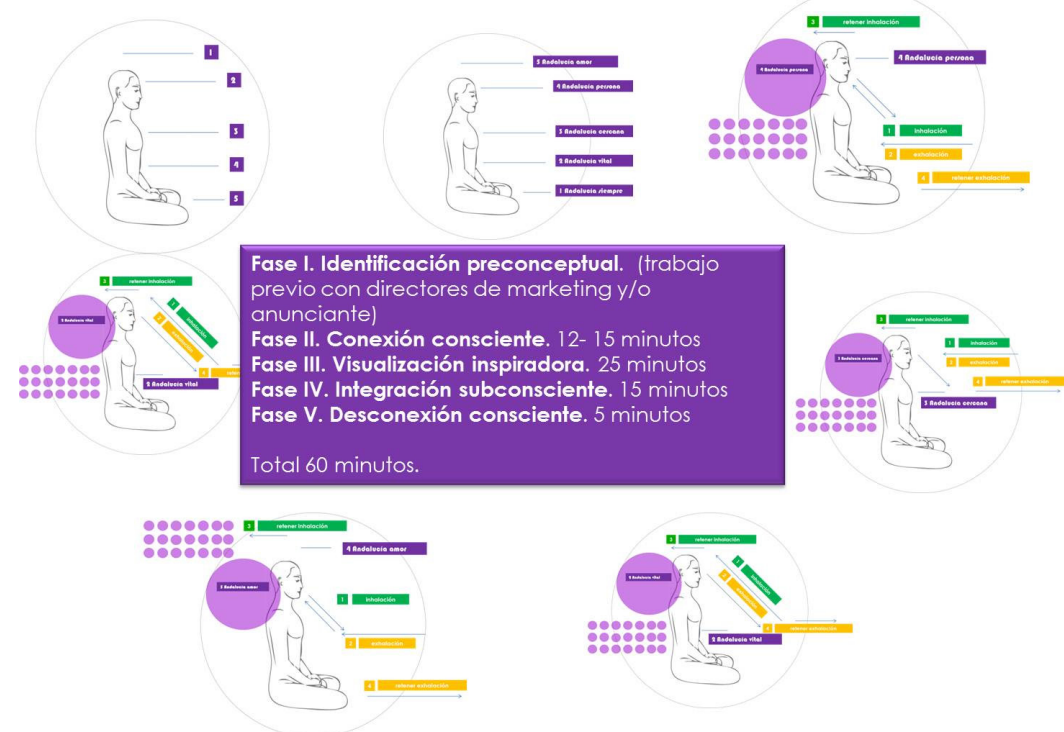

(gráfico resumen fase I, II, III, IV y V. Fuente: elaboración propia) 
Rematamos el ciclo pragmático de la campaña de dinamización turística, que hemos utilizado de ejemplo en la ponencia, con la creación de una idea creativa que integra excelentemente los ejes conceptuales definidos en las diferentes fases: "Andalucía te quiere". Después de analizar intensamente las cinco fases de la técnica de Creatividad Mindfulness (CMF), somos conscientes de que tenemos en nuestras manos una trascendental y revolucionaria metodología de estimulación e inspiración de creatividad, que podemos gestionar y configurar con ilimitadas posibilidades, y que podemos ecualizar extensamente a nuestro antojo. Una innovadora vinculación de la meditación como herramienta sutil para estimular la creatividad. Por otro lado, permite constituirse como un utensilio que despierta, y eleva, cualitativamente, nuestro nivel de consciencia creativa a la hora de inventar, idear, diseñar y configurar una pieza/campaña de publicidad. Un método que además de conseguir estimular las ideas en infinitos escenarios de inspiración inconsciente, permite lograr que la mente del creativo publicitario esté mucho más calmada y presente dentro de un entorno publicitario donde las condiciones atmosféricas suelen exigir, por defecto, altas cotas de tensión y estrés. Las posibilidades metodológicas que la técnica CMF presenta son infinitas, y mostramos simplemente una primera fase embrionaria de empleo. Se nos alumbra, por lo tanto, un nuevo, y mágico, escenario de aplicación de "consciencia creativa", que en próximas y anheladas investigaciones, tenemos pensado desvelar.

\section{Bibliografía}

BAER, R. (2003). Mindfulness training as a clinical intervention: A conceptual and empirical review. Clinical Psychology: Science and Practice.

BARNES-HOLMES, D., BARNES-HOLMES, Y., MCHUGH, L. Y HAYES, S. C. (2004). Relational FrameTheory: Some implications for understanding and treating human psychopathology.

BASSAT, Luis, (2001), El libro Rojo de la Publicidad. Plaza \& James Editores, S.A. Barcelona

BENAVIDES DELGADO, Juan, (1994), La crisis de la publicidad, Madrid, Editorial Comunicación 2000.

BROWN, K. W. Y RYAN, R. M. (2003). The bennefits of being present: Mindfulness and its role in psychological well-being. Journal of Personality and Social Psychology,

BUNGE, Mario (1981): La investigación cientifica. Ariel. Barcelona.

BUTLER-BOWDON, T. (2007). Cincuenta clásicos espirituales. Barcelona: Amat.

CALDEVILLA DOMINGUEZ, David (2004): Relaciones Públicas y su fundamentación. Vision Net. Madrid.

CALLE, Ramiro. (2000). Yoga para una vida sana. Ediciones temas de hoy S.A. Madrid.

CALLE, Ramiro. (1998). Las enseñanzas de la meditación vipassana. Barcelona: Kairós. 
CALLE, Ramiro. (2005). La meditación. Su práctica, sus métodos y sus efectos. Madrid: Jaguar.

CLEMENTE, Miguel y SANTALlA, Zuleyma, (1991), El Documento Persuasivo. Universidad Complutense de Madrid. Bilbao, Ediciones Deusto S.A.

DONDIS, D.A. (1985), La sintaxis de la imagen : introducción al alfabeto visual, Barcelona, Gustavo Gili.

FERRAZ MARTÍNEZ, Antonio, (2001), El lenguaje de la publicidad, Madrid, Arco Libros.

HART, W. (1994). La vippasana. El arte de la meditación. Madrid: Luz de Oriente. JOANNIS, Henri, (1992), El proceso de creación Publicitaria, Planteamiento, concepción y realización de los mensajes, Bilbao, Ediciones Deusto

JOANNIS, Henri, (1996) La creación Publicitaria desde la Estrategia de Marketing. Bilbao. Editorial Deusto.

LEÓN, José Luis, (1996), Los efectos de la publicidad, Madrid, Editorial Ariel.

MOLINÉ, Marçal, (2003), La comunicación activa. Publicidad sólida, Barcelona, Editorial Deusto.

VARGAS, José Jesús, (2012), Análisis de la Comunicación publicitaria gráfica: Deconstrucción de la eficiencia comunicativa gráfica: innovador método docente en el análisis y construcción de los mensajes publicitarios. Editorial: Visión Libros. Madrid.

WILSON K. G. Y LUCIANO M. C. (2002). Terapia de aceptación y compromiso (ACT). Un tratamiento conductual orientado a los valores. Madrid: Pirámide. ZUNZUNEGUI, (1984), Mirar la imagen, Bilbao, Universidad del País Vasco. 